\title{
Effect of body mass index on peak growth hormone level after growth hormone stimulation test in children with short stature
}

Na Yeong Lee ${ }^{1}$, Sung Eun Kim', Seulki Kim², Moon Bae Ahn', Shin Hee Kim', Won Kyoung $\mathrm{Cho}^{4}$, Kyoung Soon $\mathrm{Cho}^{5}$, Min Ho Jung ${ }^{6}$, ByungKyu Suh ${ }^{1}$

${ }^{1}$ Department of Pediatrics, Seoul St. Mary's Hospital, College of Medicine, The Catholic University of Korea, Seoul, Korea

${ }^{2}$ Department of Pediatrics, Eunpyeong St. Mary's Hospital, College of Medicine, The Catholic University of Korea, Seoul, Korea

${ }^{3}$ Department of Pediatrics, Incheon St. Mary's Hospital, College of Medicine, The Catholic University of Korea, Incheon, Korea

${ }^{4}$ Department of Pediatrics, St. Vincent's Hospital, College of Medicine, The Catholic University of Korea, Suwon, Korea

${ }^{5}$ Department of Pediatrics, Bucheon St. Mary's Hospital, College of Medicine, The Catholic University of Korea, Bucheon, Korea

${ }^{6}$ Department of Pediatrics, Yeouido St. Mary's Hospital, College of Medicine, The Catholic University of Korea, Seoul, Korea

Received: 17 November, 2020 Revised: 1 February, 2021

Accepted: 15 February, 2021

Address for correspondence: Won Kyoung Cho

Department of Pediatrics, St. Vincent's Hospital, College of Medicine, The Catholic University of Korea, 93, Jungbu-daero, Paldal-gu, Suwon 16247, Korea

Email:wendy626@catholic.ac.kr https://orcid.org/0000-0003-09180565
Purpose: The aim of this study is to evaluate the effect of body mass index (BMI) on peak serum growth hormone $(\mathrm{GH})$ level after $\mathrm{GH}$ stimulation test in children with short stature.

Methods: Data were obtained from retrospective medical record reviews of those who visited the pediatric endocrine clinic at St. Vincent's Hospital of Catholic University for short stature from January 2010 to June 2019. A total of 115 children ( 66 boys and 49 girls) whose height was less than the third percentile according to age and sex underwent $\mathrm{GH}$ stimulation testing.

Results: Of the 115 subjects, 47 were diagnosed with GH deficiency (GHD) and 68 were diagnosed with idiopathic short stature (ISS). In patients with GHD, weight standard deviation score (SDS) $(P<0.001)$ and BMI SDS $(P \leq 0.001)$ were higher, and free thyroxine (T4) level $(P=0.012)$ was lower than those in the ISS group. In total subjects, peak serum $\mathrm{GH}$ level after $\mathrm{GH}$ stimulation test showed negative correlations with weight SDS $(r=-0.465, P<0.001)$, BMI SDS $(r=-0.398, P<0.001)$, and thyroid stimulating hormone $(r=-0.248, P=0.008)$ and a positive correlation with free T4 $(r=0.326, P<0.001)$. In multiple regression analysis, BMI SDS $(P=0.003)$ was negatively associated with peak serum $\mathrm{GH}$ level in $\mathrm{GH}$ stimulation testing after adjusting for age, sex, pubertal status, and type of pharmacological stimulus.

Conclusion: The BMI SDS influences peak serum GH level after GH stimulation testing. We should consider BMI factors when interpreting the results of $\mathrm{GH}$ stimulation testing.

Keywords: Body mass index, Growth hormone, Short stature

\section{Highlights}

This study evaluated the effect of BMI on peak serum GH level after GH stimulation testing in short stature. The results showed that BMI SDS was negatively associated with peak serum $\mathrm{GH}$. Consideration for BMI factor is needed when interpreting the results of GH stimulation testing in short stature.

\section{Introduction}

Short stature is defined as a height less than -2 standard deviations (SDs) or less than 3 percentile ranks according to age and sex. These children are subjects for growth hormone (GH) stimulation testing to distinguish between GH deficiency (GHD) and idiopathic short stature (ISS). The diagnosis of GHD is established when peak serum GH level does not reach an arbitrary cutoff value (peak $\mathrm{GH}<10 \mathrm{ng} / \mathrm{mL}$ ) in $2 \mathrm{GH}$ stimulation tests using different stimuli. $^{1,2)}$ 
Hormonal and physiologic factors are important for $\mathrm{GH}$ secretions. Hormonal control typically is regulated by 2 counteractive hormones, GH-releasing hormone (GHRH) and somatostatin, known to stimulate and inhibit the release of $\mathrm{GH}$ from the pituitary gland, respectively. The feedback system also affects GH secretion, either by GH itself or by insulin-like growth factor 1 (IGF-1). Hormonal regulation of GH secretion is determined by these 2 processes.

Physiologic factors involved in the secretion of GH include age, onset of puberty, body weight, and so on. ${ }^{3)}$ It is known that $\mathrm{GH}$ secretion is particularly sensitive to nutritional factors and obesity. Several previous studies have reported that obesity can decrease spontaneous ${ }^{4,5)}$ and stimulated ${ }^{6,7)} \mathrm{GH}$ secretion in adults. Likewise, obese children also exhibit decreased spontaneous $^{8,9)}$ and diminished peak GH in GH stimulation testing. A negative correlation between body mass index (BMI) and peak GH response in stimulation testing has been reported. $^{10,11)}$

However, previous studies were focused on a specific group or stimulant, making it difficult to understand the effect of BMI on peak serum GH level according to group classified by diagnosis or stimulants. Therefore, the aim of this study was to evaluate the effect of BMI on peak serum GH level after GH stimulation testing in children with short stature divided into GHD and ISS groups and the type of stimulants. We interpret the results of GH stimulation testing considering the patient's physiologic status through this study.

\section{Materials and methods}

\section{Subjects}

Data were obtained from retrospective medical record reviews of those who visited the pediatric endocrine clinic at St. Vincent Hospital of Catholic University for short stature from January 2010 to June 2019. We studied 115 children (aged 3-17 years, 66 boys and 49 girls) whose height was less than the third percentile for age and sex. Patients who had other autoimmune, hematologic, or endocrine diseases were excluded. Birth weight, parental height, chronologic age, bone age, height standard deviation score (SDS), weight SDS, BMI SDS, free thyroxine (T4), triiodothyronine), thyroid stimulating hormone (TSH), cortisol, adrenocorticotropic hormone, GH, IGF-1 SDS, insulinlike growth factor binding protein-3 (IGF-BP3) SDS, and peak serum stimulated $\mathrm{GH}$ were analyzed.

\section{Stuy design}

GH stimulation tests were performed in the morning after overnight fasting. The subjects of this study underwent $\mathrm{GH}$ stimulation testing with combinations of 2 of the following 5 stimulants to assess GH secretion: levodopa (Myung In Pharm, Seoul, Korea; <15 kg: 150 mg; 15-35 kg: 250 mg; >35 kg: 500 $\mathrm{mg}$ ), clonidine (HK innoN, Seoul, Korea; $150 \mu \mathrm{g} / \mathrm{m}^{2}$ ), insulin (Lilly, Seoul, Korea; 0.05 unit/kg), glucagon (Boryung Pharm,
Seoul, Korea; $30 \mu \mathrm{g} / \mathrm{kg}$, max $1 \mathrm{mg}$ ), and arginine (Green Cross Well Being, Bundang, Korea; $0.5 \mathrm{~g} / \mathrm{kg}$, max $30 \mathrm{~g}$ ). Two stimulants were tested at intervals of more than 24 hours. Blood samples were collected at the time of administration of the stimuli and at 30,60, 90, and 120 minutes after administration of stimuli to measure peak serum GH level. GHD was defined when peak serum GH level was less than $10 \mathrm{ng} / \mathrm{mL}$ after stimulation with a combination of 2 separate simulants. ${ }^{1)}$ If peak serum GH level exceeded $10 \mathrm{ng} / \mathrm{mL}$ in even one stimulation test, the child was diagnosed with ISS.

\section{Anthropometric and laboratory measurements}

Height was measured to $0.1 \mathrm{~cm}$ with a Harpenden Stadiometer (Holtain Ltd., Wales, UK) and weight was measured to 0.1 kg using a CAS scale (CAS, Seoul, Korea). All anthropometry data were calculated to a $z$-score based on 2017 Korean National Growth chart reference data. ${ }^{12}$ Serum GH level was measured with immunoradiometric assay (Immulite 2000, Siemens Medical Solutions Diagnostics, Bracknell, UK). Obese in this study means BMI $>$ 85th percentile for one's age and sex, while puberty was defined as more advanced than sex maturity rating 2 .

\section{Statistical analysis}

Statistical analysis was performed using IBM SPSS Statistics ver. 24.0 (IBM Co., Armonk, NY, USA). Comparisons between groups were performed using independent $t$-test or MannWhitney $U$-test and Pearson chi-square test. Correlation analysis was performed using the Pearson correlation coefficient. Univariate linear regression analysis was performed to determine variables associated with peak GH. Multiple regression analysis was used to identify independent predictors of peak GH response to stimulants. Significance was defined as $P<0.05$. Results were described as mean \pm standard deviation unless otherwise stated.

\section{Results}

\section{Clinical and biochemical characteristics of the subjects}

The study population included 66 males (57.4\%) and 49 females $(42.6 \%)$ with a mean age of $9.06 \pm 3.35$ years. Of the 115 patients, 47 (40.9\%) were diagnosed with GHD and 68 (59.1\%) were diagnosed with ISS. Patients diagnosed with GHD had higher weight SDS $(P<0.001)$ and BMI SDS $(P \leq 0.001)$ and lower free T4 level than patients diagnosed with ISS $(P=0.012)$. There was no statistically significant difference in TSH, GH, IGF-1 SDS, and IGF-BP3 between the GHD and ISS groups (Table 1). 
Table 1. Clinical and biochemical characteristics of subjects

\begin{tabular}{|c|c|c|c|c|}
\hline Characteristic & All patients & GHD & ISS & $P$-value \\
\hline Number (\%) & 115 & $47(40.9)$ & $68(59.1)$ & \\
\hline Sex, male:female & $66: 49$ & $22: 25$ & $44: 24$ & 0.056 \\
\hline Birth weight (kg) & $2.84 \pm 0.66$ & $2.86 \pm 0.55$ & $2.83 \pm 0.72$ & 0.987 \\
\hline Mother's height (cm) & $155.71 \pm 5.02$ & $156.28 \pm 5.42$ & $155.30 \pm 4.71$ & 0.318 \\
\hline Father's height (cm) & $168.36 \pm 5.48$ & $169.04 \pm 5.33$ & $167.86 \pm 5.57$ & 0.299 \\
\hline Mid parental height (cm) & $162.81 \pm 6.96$ & $162.08 \pm 6.60$ & $163.3 \pm 7.21$ & 0.340 \\
\hline Age (yr) & $9.06 \pm 3.35$ & $8.97 \pm 3.09$ & $9.11 \pm 3.53$ & 0.937 \\
\hline Bone age (yr) & $7.96 \pm 3.47$ & $7.87 \pm 3.33$ & $8.04 \pm 3.60$ & 0.826 \\
\hline Puberty ${ }^{*}$ & $18(15.6)$ & $7(14.8)$ & $11(16.1)$ & 0.636 \\
\hline height SDS & $-2.62 \pm 0.54$ & $-2.52 \pm 0.52$ & $-2.68 \pm 0.56$ & 0.091 \\
\hline Weight SDS & $-1.95 \pm 0.97$ & $-1.50 \pm 0.96$ & $-2.27 \pm 0.84$ & $<0.001$ \\
\hline BMI SDS & $-0.67 \pm 1.18$ & $-0.15 \pm 1.14$ & $-1.03 \pm 1.08$ & $\leq 0.001$ \\
\hline Obese $^{\dagger}$ & $7(6.0)$ & $5(10.6)$ & $2(2.9)$ & 0.098 \\
\hline Free T4 (ng/dL) & $1.05 \pm 0.19$ & $1.00 \pm 0.21$ & $1.09 \pm 0.17$ & 0.012 \\
\hline TSH (mIU/L) & $2.23 \pm 1.21$ & $2.39 \pm 1.20$ & $2.12 \pm 1.20$ & 0.203 \\
\hline Cortisol $(\mu \mathrm{g} / \mathrm{dL})$ & $5.93 \pm 2.86$ & $6.67 \pm 3.41$ & $5.12 \pm 1.84$ & 0.115 \\
\hline ACTH (pg/mL) & $18.16 \pm 16.93$ & $17.99 \pm 18.54$ & $18.33 \pm 15.43$ & 0.690 \\
\hline basal GH (ng/mL) & $2.10 \pm 2.86$ & $1.59 \pm 2.24$ & $2.44 \pm 3.18$ & 0.132 \\
\hline IGF-1 SDS & $-0.88 \pm 0.80$ & $-1.01 \pm 0.78$ & $-0.80 \pm 0.80$ & 0.118 \\
\hline IGF-BP3 SDS & $1.82 \pm 1.61$ & $1.75 \pm 1.56$ & $1.87 \pm 1.65$ & 0.687 \\
\hline
\end{tabular}

Values are presented as number (\%) or mean \pm standard deviation.

GHD, growth hormone deficiency; ISS, idiopathic short stature; SDS, standard deviation score; BMI, body mass index; free T4, free thyroxine; TSH, thyroid stimulating hormone; ACTH, adrenocorticotropic hormone; GH, growth hormone; IGF-1, insulin-like growth factor-1; IGF-BP3, insulin-like growth factor binding protein.

"Puberty: pubertal status more than SMR 2. ${ }^{\dagger}$ Obese: BMI > 85th percentile for one's age and sex.

Table 2. Peak serum growth hormone level $(\mathrm{ng} / \mathrm{mL})$ induced by each stimuli after $\mathrm{GH}$ stimulation test

\begin{tabular}{lcccc}
\hline Type of stimulants & All patients & GHD & ISS & P-value \\
\hline Dopamine induced & $6.25(0.53-36.00)$ & $4.88(0.53-9.82)$ & $9.66(1.81-36.00)$ & $<0.001$ \\
Clonidine induced & $13.6(7.77-32.40)$ & - & $13.60(7.77-32.40)$ & - \\
Glucagon induced & $8.67(2.20-20.80)$ & $6.49(2.20-8.90)$ & $11.45(2.95-20.80)$ & 0.026 \\
Insulin induced & $10.79(0.15-40.00)$ & $8.16(0.15-9.60)$ & $13.6(2.83-40.00)$ & $<0.001$ \\
Arginine induced & $7.10(0.86-18.22)$ & $4.75(0.86-9.84)$ & $11.34(5.73-18.22)$ & $<0.001$ \\
\hline
\end{tabular}

Values are presented as median (range).

$\mathrm{GH}$, growth hormone; GHD, growth hormone deficiency; ISS, idiopathic short stature.

\section{Comparison of peak serum $\mathrm{GH}$ level after $\mathrm{GH}$ stimulation test by type of stimulant}

For the 115 subjects, a total of $225 \mathrm{GH}$ stimulation tests was performed (in 5 cases, we confirmed that the peak GH level caused by the first stimulant was greater than $10 \mathrm{ng} / \mathrm{mL}$ in that day, so a second study was not performed). Dopamine, clonidine, glucagon, insulin, and arginine were used in 111 (49\%), 7 (3\%), 19 (9\%), 56 (25\%), and 32 cases (14\%), respectively. Peak serum GH level in the GHD group simulated by dopamine $(P<0.001)$, glucagon $(P=0.011)$, insulin $(P<0.001)$, and arginine $(P<0.001)$ was lower than that in the ISS group (Table 2 ).

\section{Correlations between variables and peak serum GH level after $\mathrm{GH}$ stimulation testing}

Peak serum GH level after GH stimulation testing exhibited negative correlations with weight SDS $(r=-0.465, P<0.001)$, BMI SDS $(r=-0.398, P<0.001)$, and TSH $(r=-0.248, P=0.008)$. On the other hand, free T4 showed a positive correlation with peak serum GH $(r=0.326, P<0.001)$. However, peak serum $\mathrm{GH}$ level after $\mathrm{GH}$ stimulation testing did not show a statistically significant association with age, IGF-1 SDS, or IGF-BP3 SDS. When the subjects were divided into GHD and ISS, both groups exhibited negative correlations of peak serum GH level in weight SDS (GHD: $r=-0.312, P=0.033$; ISS: $r=-0.354, P=0.003$ ), BMI SDS (GHD: $r=-0.313, P=0.032$; ISS: $r=-0.246, P=0.043$ ), and TSH (GHD: $r=-0.299, P=0.046$; ISS: $r=-0.244, P=0.046$ ) (Table 3 ). When we divided the subjects by subgroups of stimulants, BMI SDS demonstrated a significant correlation with peak GH in groups using dopamine $(r=-0.419, P \leq 0.001)$, insulin $(r=-$ $0.271, P=0.044)$, and arginine $(r=-0.368, P=0.038)$. Meanwhile, clonidine $(r=0.071, P=0.880)$ and glucagon $(r=0.186, P=0.447)$ did not exhibit a significant correlation. 
Table 3. Correlation between variables and peak serum $\mathrm{GH}$ level after $\mathrm{GH}$ stimulation test

\begin{tabular}{|c|c|c|c|c|c|c|}
\hline \multirow{3}{*}{ Variable } & \multicolumn{6}{|c|}{ Stimulated peak serum GH } \\
\hline & \multicolumn{2}{|c|}{ Total } & \multicolumn{2}{|c|}{ GHD } & \multicolumn{2}{|c|}{ ISS } \\
\hline & $r$ & $P$-value & $r$ & $P$-value & $r$ & $P$-value \\
\hline Age & 0.044 & 0.122 & -0.149 & 0.317 & 0.077 & 0.531 \\
\hline Height SDS & -0.262 & 0.075 & 0.049 & 0.746 & -0.279 & 0.054 \\
\hline Weight SDS & -0.465 & $<0.001$ & -0.312 & 0.033 & -0.354 & 0.003 \\
\hline BMI SDS & -0.398 & $<0.001$ & -0.313 & 0.032 & -0.246 & 0.043 \\
\hline Free T4 & 0.326 & $<0.001$ & 0.141 & 0.354 & 0.314 & 0.010 \\
\hline TSH & -0.248 & 0.008 & -0.299 & 0.046 & -0.244 & 0.046 \\
\hline IGF-1 SDS & -0.024 & 0.804 & 0.062 & 0.683 & -0.191 & 0.125 \\
\hline IGF-BP3 SDS & -0.142 & 0.144 & 0.225 & 0.138 & -0.327 & 0.009 \\
\hline
\end{tabular}

$\mathrm{GH}$, growth hormone; GHD, growth hormone deficiency; ISS, idiopathic short stature; SDS, standard deviation score; BMI, body mass index; Free T4, free thyroxine; TSH, thyroid stimulating hormone; IGF-1, insulin-like growth factor-1; IGF-BP3, insulin-like growth factor binding protein.

Table 4. Multiple regression analysis of BMI SDS and peak serum GH level after $\mathrm{GH}$ stimulation test

\begin{tabular}{lccc}
\hline Parameter & $\beta$ coeffient & Standard error & $P$-value \\
\hline Total & & & \\
BMI SDS & -2.915 & 0.876 & 0.003 \\
Free T4 & 6.092 & 6.531 & 0.359 \\
TSH & -2.208 & 1.153 & 0.859 \\
GHD & & & \\
BMI SDS & -1.118 & 0.403 & 0.027 \\
TSH & -0.895 & 0.751 & 0.272 \\
ISS & & & \\
BMI SDS & -2.663 & 2.758 & 0.353 \\
Free T4 & 5.905 & 4.225 & 0.167 \\
TSH & 0.973 & 2.654 & 0.720 \\
IGF-BP3 & 0.087 & 1.708 & 0.960 \\
\hline
\end{tabular}

Multiple regression analysis contained the following independent variables: age, sex, pubertal status, type of stimulant and significant predictors in univariate regression analysis. $\beta$ coefficient as unstandardized.

BMI, body mass index; SDS, standard deviation score; GH, growth hormone; free T4, thyroxine; GHD, growth hormone deficiency; TSH, thyroid stimulating hormone; IGF-BP3, insulin-like growth factor binding protein 3.

\section{Multiple regression analysis of BMI SDS and peak GH level after $\mathrm{GH}$ stimulation test}

In univariate regression analysis, type of stimulants $(P=0.042)$, BMI SDS $(P<0.001)$, free T4 $(P<0.001)$, and TSH $(P=0.008)$ were associated with peak serum $\mathrm{GH}$ level after $\mathrm{GH}$ stimulation test. Type of stimulant was not a predictive factor of peak GH. In multiple regression analysis, BMI SDS $(P=0.003)$ was negatively associated with peak serum GH level after GH stimulation test after adjusting for age, sex, pubertal status, and type of pharmacological stimulus. In the GHD group, BMI SDS $(P=0.027)$ was negatively associated with peak serum $\mathrm{GH}$ level after GH stimulation testing. On the other hand, in the ISS group, there was no statistically significant association of peak serum GH level with BMI SDS (Table 4).

\section{Discussion}

The results of our study demonstrated that BMI SDS was a significant determinant of peak serum GH level after GH stimulation testing. BMI SDS, weight SDS, and free T4 level were significantly different between the GHD and ISS groups. In GH stimulation testing using dopamine, insulin, and arginine, peak serum GH level exhibited a negative correlation with weight SDS and BMI SDS. BMI SDS was the independent predictor of peak serum GH level in multiple regression analysis.

Previous studies have shown the relationship between obesity and GH secretion. It has been shown that adults with obesity have abnormal baseline GH secretion, and that obesity also is associated with impairment of GH response to GH stimulants. ${ }^{13-15)}$ These same results have been obtained for children. However, there are few short stature child patients who can be classified as overweight and obese compared to adults. In addition, standard values for pediatric BMI level differ by gender and age. Therefore, BMI SDS has been used to prove the effect of BMI on GH secretion in children. Several studies have reported on the relationship between BMI SDS and peak GH in children. ${ }^{16-20)}$ Although each study used a different number of subjects, different period of study, or different number of stimulants for analysis, they all demonstrated the common relationship between BMI SDS and peak serum GH.

Our results showed similar trends to previous studies about the effects of BMI on peak serum GH level. However, our study was different from previous studies in that we divided subjects into GHD and ISS groups and interpreted the effect of BMI SDS on peak serum GH level by group, separately. The results of our study showed that BMI SDS was associated with peak serum GH level in both GHD and ISS groups, and BMI SDS was an independent predictor of peak serum GH level in the total group and GHD group but not in the ISS group.

Since we could not diagnose GHD using levels of hormones like GH and IGF-1 with a single blood draw, confirmation of GHD relied on the $\mathrm{GH}$ response to $\mathrm{GH}$ stimulation test using 2 stimulants. However, the issue of reliability of GH stimulation testing has been continuously raised. Several studies ${ }^{21-24)}$ have 
reported that some patients diagnosed with isolated GHD have normal responses to stimulants when retested at the end of treatment or during treatment. This indicates that diagnosis of GHD could be a false positive. In this respect, the results of our study suggest that that BMI could be an important factor affecting GH responses to simulation testing in children with short stature, possibly leading to a false diagnosis of GHD. Therefore, more attention is needed to interpret the results of GH stimulation testing for a subject with higher BMI SDS.

In this study, we also divided subjects by stimulants and confirmed that BMI SDS exhibited a correlation with peak serum GH level when using dopamine, insulin, and arginine but not glucagon and clonidine. The mechanism of action of each stimulant is as follows. Dopamine acts on an alpha-adrenergic receptor of the central nervous system (CNS) and promotes the release of GHRH. The role of insulin in GH stimulation testing is to create a hypoglycemic state that could stimulate alphaadrenergic receptors in the CNS and promote GHRH release from the hypothalamus. Glucagon and clonidine also act on the alpha-adrenergic system of the CNS to release GHRH from the hypothalamus and stimulate secretion of GH. The mechanism of arginine involves reduction in somatostatin release and induction of GH secretion. ${ }^{25)}$ In our study, BMI SDS exhibited a significant correlation with peak $\mathrm{GH}$ in groups using dopamine, insulin, and arginine as stimulants. These groups consisted of 30 or more subjects. We suggest that these results could be caused by the number of subjects. Dopamine, insulin, and arginine tests were performed with sufficient participants compared to the glucagon and clonidine groups. To analyze the cause of these results and determine the possible reasons, more research is needed with sufficient numbers of subjects.

The reason why obese people exhibit impaired GH secretion is not clear. However, high free fatty acid levels associated with actions of lipolysis $^{26,27)}$ and elevated serum insulin actions on pituitary receptors that directly affect to suppression of GH secretion ${ }^{28)}$ were thought to be involved in the pathogenesis of insufficient GH secretion in obese patients. One more thing that needed to be analyzed in this study was the association of TSH with peak serum GH level. Studies on the positive correlation between obesity and TSH in euthyroid individuals have been performed. It is believed that obesity can influence the hypothalamus-pituitary-thyroid axis. ${ }^{29-33)}$ In our study, TSH exhibited a negative correlation with peak serum GH in both GHD and ISS groups. Although a few subjects in our study were overweight and obese, the relationship between BMI and TSH must be considered. Regarding the positive relationship between TSH and obesity and the negative correlation between obesity and peak serum GH level, the negative correlation of TSH with peak serum GH level could be explained.

There are several limitations in our study. First, since we used retrospective clinical data and researched with limited data, our sample size was not large enough to analyze each subgroup separately. Additional studies including a larger number of subjects must be conducted to compare results. Second, this is a retrospective, cross-sectional designed study, and we could not determine the causality of higher BMI and GHD. It also was difficult to exclude the possibility that patients with true GHD might have higher BMI, influencing our results. Despite several limitations, there are strengths of our study. Regardless of stimulant type, when a certain number of subjects was secured, BMI SDS is associated with peak GH. The test results of hormones that could affect growth and GHs, such as thyroid hormone, were analyzed together. In conclusion, our study confirmed that BMI could affect peak serum GH level. Therefore, we should consider BMI factors affecting peak GH when diagnosing GHD, especially for children with higher BMI.

\section{Ethical statement}

The study was approved by the Institutional Review Board of St. Vincent's Hospital of Catholic University (IRB No. VC19RESI0296).

\section{Conflict of interest}

No potential conflict of interest relevant to this article was reported.

\section{References}

1. Consensus guidelines for the diagnosis and treatment of growth hormone (GH) deficiency in childhood and adolescence: summary statement of the GH Research Society. GH Research Society. J Clin Endocrinol Metab 2000;85:3990-3.

2. Cappa M, Loche S. Evaluation of growth disorders in the paediatric clinic. J Endocrinol Invest 2003;26:54-63.

3. Iranmanesh A, Lizarralde G, Veldhuis JD. Age and relative adiposity are specific negative determinants of the frequency and amplitude of growth hormone $(\mathrm{GH})$ secretory bursts and the half-life of endogenous GH in healthy men. J Clin Endocrinol Metab 1991;73:1081-8.

4. Weltman A, Weltman JY, Watson Winfield DD, Frick K, Patrie J, Kok P, et al. Effects of continuous versus intermittent exercise, obesity, and gender on growth hormone secretion. J Clin Endocrinol Metab 2008;93:471120.

5. Riedel M, Hoeft B, Blum WF, von zur Muhlen A, Brabant G. Pulsatile growth hormone secretion in normal-weight and obese men: differential metabolic regulation during energy restriction. Metabolism 1995;44:605-10.

6. Carmichael JD, Danoff A, Milani D, Roubenoff R, Lesser ML, Livote E, et al. GH peak response to GHRH-arginine: relationship to insulin resistance and other cardiovascular risk factors in a population of adults aged 50-90. Clin Endocrinol (Oxf) 2006;65:169-77.

7. Williams T, Berelowitz M, Joffe SN, Thorner MO, Rivier J, Vale W, et al. Impaired growth hormone responses to growth hormone-releasing factor in obesity. A pituitary 
defect reversed with weight reduction. N Engl J Med 1984;311:1403-7.

8. Argente J, Caballo N, Barrios V, Munoz MT, Pozo J, Chowen JA, et al. Multiple endocrine abnormalities of the growth hormone and insulin-like growth factor axis in patients with anorexia nervosa: effect of short-and long-term weight recuperation. J Clin Endocrinol Metab 1997;82:2084-92.

9. Kasa-Vubu JZ, Barkan A, Olton P, Meckmongkol T, Carlson NE, Foster CM. Incomplete modified fast in obese early pubertal girls leads to an increase in 24-hour growth hormone concentration and a lessening of the circadian pattern in leptin. J Clin Endocrinol Metab 2002;87:188593.

10. Misra M, Bredella MA, Tsai P, Mendes N, Miller KK, Klibanski A. Lower growth hormone and higher cortisol are associated with greater visceral adiposity, intramyocellular lipids, and insulin resistance in overweight girls. Am J Physiol Endocrinol Metab 2008;295:E385-92.

11. Radetti G, Bozzola M, Pasquino B, Paganini C, Aglialoro A, Livieri C, et al. Growth hormone bioactivity, insulin-like growth factors (IGFs), and IGF binding proteins in obese children. Metabolism 1998;47:1490-3.

12. Korea Disease Control and Prevention Agency. The 2017 Korean National Growth Charts for children and adolescents [Internet]. Osong (Korea): Korea Disease Control and Prevention Agency; 2017 [cited 2020 Nov 2]. Available from: http://www.cdc.go.kr/contents. es? $\mathrm{mid}=\mathrm{a} 20303030400$.

13. Colao A, Di Somma C, Savastano S, Rota F, Savanelli MC, Aimaretti G, et al. A reappraisal of diagnosing GH deficiency in adults: role of gender, age, waist circumference, and body mass index. J Clin Endocrinol Metab 2009;94:4414-22

14. Makimura H, Stanley T, Mun D, You SM, Grinspoon S. The effects of central adiposity on growth hormone (GH) response to GH-releasing hormone-arginine stimulation testing in men. J Clin Endocrinol Metab 2008;93:4254-60.

15. Bonert VS, Elashoff JD, Barnett P, Melmed S. Body mass index determines evoked growth hormone $(\mathrm{GH})$ responsiveness in normal healthy male subjects: diagnostic caveat for adult GH deficiency. J Clin Endocrinol Metab 2004;89:3397-401.

16. Stanley TL, Levitsky LL, Grinspoon SK, Misra M. Effect of body mass index on peak growth hormone response to provocative testing in children with short stature. J Clin Endocrinol Metab 2009;94:4875-81.

17. Loche S, Guzzetti C, Pilia S, Ibba A, Civolani P, Porcu M, et al. Effect of body mass index on the growth hormone response to clonidine stimulation testing in children with short stature. Clin Endocrinol (Oxf) 2011;74:726-31.

18. Lee HS, Hwang JS. Influence of body mass index on growth hormone responses to classic provocative tests in children with short stature. Neuroendocrinology 2011;93:259-64.

19. Yang A, Cho SY, Kwak MJ, Kim SJ, Park SW, Jin DK, et al.
Impact of BMI on peak growth hormone responses to provocative tests and therapeutic outcome in children with growth hormone deficiency. Sci Rep 2019;9:16181.

20. Lee J, Yoon J, Kang MJ, Lee YA, Lee SY, Shin CH, et al. Influence of body mass index on the growth hormone response to provocative testing in short children without growth hormone deficiency. J Korean Med Sci 2013;28:1351-5.

21. Juul A, Kastrup KW, Pedersen SA, Skakkebaek NE. Growth hormone $(\mathrm{GH})$ provocative retesting of 108 young adults with childhood-onset GH deficiency and the diagnostic value of insulin-like growth factor I (IGF-I) and IGFbinding protein-3. J Clin Endocrinol Metab 1997;82:1195201.

22. Maghnie M, Strigazzi C, Tinelli C, Autelli M, Cisternino M, Loche S, et al. Growth hormone (GH) deficiency (GHD) of childhood onset: reassessment of GH status and evaluation of the predictive criteria for permanent GHD in young adults. J Clin Endocrinol Metab 1999;84:1324-8.

23. Loche S, Bizzarri C, Maghnie M, Faedda A, Tzialla C, Autelli $\mathrm{M}$, et al. Results of early reevaluation of growth hormone secretion in short children with apparent growth hormone deficiency. J Pediatr 2002;140:445-9.

24. Cacciari E, Tassoni P, Cicognani A, Pirazzoli P, Salardi S, Balsamo A, et al. Value and limits of pharmacological and physiological tests to diagnose growth hormone $(\mathrm{GH})$ deficiency and predict therapy response: first and second retesting during replacement therapy of patients defined as GH deficient. J Clin Endocrinol Metab 1994;79:1663-9.

25. Volta C, Bernasconi S, Iughetti L, Ghizzoni L, Rossi M, Costa M, et al. Growth hormone response to growth hormone-releasing hormone (GHRH), insulin, clonidine and arginine after GHRH pretreatment in obese children: evidence of somatostatin increase? Eur J Endocrinol 1995;132:716-21.

26. Casanueva FF, Villanueva L, Dieguez C, Diaz Y, Cabranes JA, Szoke B, et al. Free fatty acids block growth hormone $(\mathrm{GH})$ releasing hormone-stimulated GH secretion in man directly at the pituitary. J Clin Endocrinol Metab 1987;65:634-42

27. Maccario M, Procopio M, Loche S, Cappa M, Martina V, Camanni F, et al. Interaction of free fatty acids and arginine on growth hormone secretion in man. Metabolism 1994;43:223-6.

28. Luque RM, Kineman RD. Impact of obesity on the growth hormone axis: evidence for a direct inhibitory effect of hyperinsulinemia on pituitary function. Endocrinology 2006;147:2754-63.

29. Kitahara CM, Platz EA, Ladenson PW, Mondul AM, Menke A, Berrington de González A. Body fatness and markers of thyroid function among U.S. men and women. PLoS One 2012;7:e34979.

30. Bétry C, Challan-Belval MA, Bernard A, Charrié A, Drai J, Laville M, et al. Increased TSH in obesity: evidence for a BMI-independent association with leptin. Diabetes Metab 
2015;41:248-51.

31. Kim JM, Kim BH, Lee H, Kim EH, Kim M, Kim JH, et al. The relationship between thyroid function and different obesity phenotypes in Korean euthyroid adults. Diabetes Metab J 2019;43:867-78.

32. Witkowska-Sędek E, Kucharska A, Rumińska M, Pyrżak
B. Thyroid dysfunction in obese and overweight children. Endokrynol Pol 2017;68:54-60.

33. Licenziati MR, Valerio G, Vetrani I, De Maria G, Liotta F, Radetti G. Altered thyroid function and structure in children and adolescents who are overweight and obese: reversal after weight loss. J Clin Endocrinol Metab 2019;104:2757-65. 